\title{
Erratum to: Impedance spectroscopy study on the ionic conductivity processes of the novel LiFeVO4 phase
}

\author{
Aristotelis Kazakopoulos • Orestis Kalogirou
}

Published online: 16 June 2011

(C) Springer-Verlag 2011

\section{Erratum to: Ionics}

\section{DOI 10.1007/s11581-010-0428-z}

In the paper of Ref. [1], we presented results of studies detailing the electrical properties of a vanadate phase then believed to be a novel compound with the chemical formula $\mathrm{LiFeVO}_{4}$. Since the time of that publication, we have endeavored to probe further into the properties of this material to elucidate the relationships between its structural and electrical properties. This erratum presents recent results that put in doubt the nature of the phase produced and reported in [1]. Our finding is that the primary phase could not be $\mathrm{LiFeVO}_{4}$ as first believed, but instead a $\mathrm{LiVO}_{3}$ and $\alpha-\mathrm{Fe}_{2} \mathrm{O}_{3}$ composite. At the time our work was submitted to Ionics there were only two reports claiming the existence of a novel compound with the chemical formula $\mathrm{LiFeVO}_{4}[2,3]$. At that time we were studying the conductivity processes in a whole series of $\mathrm{LiMVO}_{4}$ $(\mathrm{M}=\mathrm{Ni}, \mathrm{Co}, \mathrm{Zn}, \mathrm{Mn}, \mathrm{Mg})$ and therefore we found it intriguing to further investigate the conductivity properties of a novel vanadate. As we mention in [1] "Impedance spectroscopy study of the compound $\mathrm{LiFeVO}_{4}$ has been performed in [11, Ref. 2 of this erratum] and the equivalent

The online version of the original article can be found at http://dx.doi. org/10.1007/s11581-010-0428-z.

A. Kazakopoulos

Departement of Electronics, T.E.I. of Thessaloniki,

57400 Thessaloniki, Greece

\section{O. Kalogirou $(\bowtie)$}

Department of Physics, Aristotle University of Thessaloniki, 54124 Thessaloniki, Greece

e-mail: orestis.kalogirou@physics.auth.gr circuits of the compound have been given at 25, 50, 75, 100,125 and $250^{\circ} \mathrm{C}$. In that paper a study of the variation of impedance versus temperature at 50,100,125 and $250^{\circ} \mathrm{C}$ is presented. In our present work an impedance spectroscopy study of the novel compound $\mathrm{LiFeVO}_{4}$ is presented based on a different methodology and perspective than that reported in [11]." Additionally we expanded the temperature range up to $500^{\circ} \mathrm{C}$. In Ref. [2] a detailed description of the reaction processes and of the characterization (though preliminary) of the reaction product were presented. In the case of the discovery of a new phase it is common that a provisional structural characterization is provided and in a follow-up work of the same or other authors the actual structural description is given. Based on that we repeated the reaction described in [2] and found that the XRD pattern of our product was identical to that given in [2] unfortunately disregarding the obvious fact that the latter is smoothed. However, we stated in [1] "The main diffraction peaks in Fig. 2 completely coincide with the XRD pattern given in Ref. [11] (in a 20-80 interval) and could be indexed according to that preliminary study in the orthorhombic system, see Fig. 2. In our pattern there are some small peaks which cannot be seen in the smoothed pattern provided in [11,13]. Nevertheless, there is not another source of information in literature for the XRD study of $\mathrm{LiFeVO}_{4}$ ". It turns out that there was a simple reason for the existence of these unidentified peaks.

Recently, we realized that the XRD pattern of our product can be also indexed considering a two phase system consisting of $\mathrm{LiVO}_{3}$ and $\alpha-\mathrm{Fe}_{2} \mathrm{O}_{3}$ [4]. Therefore, we performed a Rietveld analysis on the same X-ray diffraction pattern which has been reported in [1]. Thus, that XRD pattern was treated as a mixture of two phases, $\alpha-\mathrm{Fe}_{2} \mathrm{O}_{3}$ and $\mathrm{LiVO}_{3}$. For the latter the structure model described by Muller et al. [5] was 


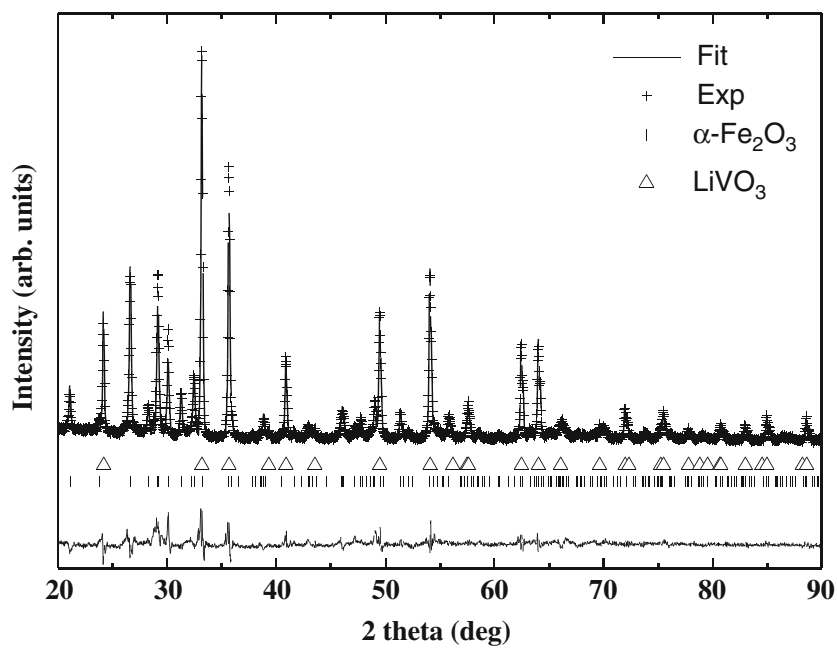

Fig. 1 XRD spectrum refined by the Rietveld method. (+) experimental points, the continuous line corresponds to the calculated spectrum, triangles at the bottom indicate the position of Bragg peaks for $\alpha-\mathrm{Fe}_{2} \mathrm{O}_{3}$ (above, fewer peaks due to higher symmetry) and vertical bars at the bottom $\mathrm{LiVO}_{3}$ (below). The continuous line at the bottom is the difference between the experimental intensity values and the calculated one

used. Rietveld analysis was carried out to fit the data with the program GSAS $[6,7]$ and extract the crystallographic and compositional parameters of the two phases, Fig. 1. The $\alpha-$ $\mathrm{Fe}_{2} \mathrm{O}_{3}$ phase is crystallized in $\mathrm{R}-32 / \mathrm{c}$ space group (No $167)$ and the crystallographic parameters which were derived from the fit were $a=b=5.03 \AA, c=13.74 \AA$ and cell volume $301.414 \AA^{3}$. The $\mathrm{LiVO}_{3}$ phase is described by the $\mathrm{C} 12 / \mathrm{c} 1$ space group (No 15) and the crystallographic parameters were found to $\mathrm{be} a=10.15 \AA, \mathrm{b}=8.42 \AA, \mathrm{c}=5.88 \AA$, $\beta=110.46^{\circ}$ and cell volume $470.911 \AA^{3}$, in agreement with the literature.

The reduced chi-square value of the fit was 3.593. It turned out that the material was indeed composed by the two phases described above with 43.7 wt. $\% \mathrm{Fe}_{2} \mathrm{O}_{3}$ and
$56.3 \mathrm{wt} . \% \mathrm{LiVO}_{3}$. The theoretical values for the composition of the sample are 43 and 57 wt.\% by taking into account the chemical reaction

$$
\mathrm{Li}_{2} \mathrm{CO}_{3}+\mathrm{Fe}_{2} \mathrm{O}_{3}+\mathrm{V}_{2} \mathrm{O}_{5}-->2 \mathrm{LiVO}_{3}+\mathrm{Fe}_{2} \mathrm{O}_{3}+\mathrm{CO}_{2}
$$

practically identical with our results. It is profound that crystallographically the material should be described as a mixture of the trigonal $\alpha-\mathrm{Fe}_{2} \mathrm{O}_{3}(\mathrm{R}-3 \mathrm{c} \mathrm{SG})$ and the monoclinic $\mathrm{LiVO}_{3}(\mathrm{C} 2 / \mathrm{c} \mathrm{SG})$ phases. In the meantime two publications have re-examined the synthesis of $\mathrm{LiFeVO}_{4}$ confirming that under the reaction conditions used in our paper a mixture of $\alpha-\mathrm{Fe}_{2} \mathrm{O}_{3}$ and $\mathrm{LiVO}_{3}$ is obtained $[8,9]$. Therefore, our results of Ref. 1 on the ionic conductivity behaviour of this system should be considered as the electrical properties of $\alpha-\mathrm{Fe}_{2} \mathrm{O}_{3} /$ $\mathrm{LiVO}_{3}$ composite and not of " $\mathrm{LiFeVO}$ ".

Acknowledgements Dr. H.B. Yahia (Research Institute for Ubiquitous Energy Devices, National Institute of Advanced Industrial Science and Technology (AIST), 1-8-31 Midorigaoka, Ikeda, Osaka, Japan) is acknowledged for helpful discussions. Dr. C. Sarafidis (Dept. of Physics, Aristotle University of Thessaloniki, Greece) is acknowledged for carefully performing Rietveld analysis.

\section{References}

1. Kazakopoulos A, Kalogirou O (2010) Ionics 16:289-295

2. Ram M, Choudhary RNP, Thakur AK (2006) Adv Appl Ceram 105:140-147

3. Ram M (2008) Mater Chem Phys 109:465-468

4. Yahia $\mathrm{HB}$, private communication

5. Muller Ch, Valmalette JC, Soubeyroux JL, Bouree F, Gavarri JR (2006) J Solid State Chem 156:379-389

6. Larson AC, Von Dreele RB (2000) General Structure Analysis System (GSAS), Los Alamos National Laboratory Report LAUR: 86-748

7. Toby BH (2001) J Appl Cryst 34:210-213

8. Yahia HB, Shikano M, Tatsumi K (2011) Mater Chem Phys. doi:10.1016/j.matchemphys.2011.02.063

9. Clemens O, Bauer M, Haberkorn R, Beck HP (2011) Z Anorg Allg Chem. doi:10.1002/zaac.201100037 